\title{
A Comparison of the Risks and Benefits of Nursing Bedside Shift Report vs. Traditional Shift Report: A Systematic Review of the Literature
}

\author{
Courtney L. Williams ${ }^{1}$ \\ ${ }^{1}$ Cardiac Telemetry Unit, Lakeland Health, Saint Joseph, Michigan, USA \\ Correspondence: Sam Abraham, Associate Professor of Nursing, 1001 Bethel Circle, Bethel College School of \\ Nursing, Mishawaka, Indiana, 46545, USA.
}

Received: April 23, 2018

Accepted: May 9, 2018

Online Published: May 14, 2018

doi:10.20849/ijsn.v3i2.382

URL: https://doi.org/10.20849/ijsn.v3i2.382

\begin{abstract}
Background: Shift report is one of the most important factors in patient care to ensure the oncoming nurse can properly care for the patient. Situation, Background, Assessment, and Recommendation (SBAR) is a communication tool that enables the safe transfer of pertinent information to ensure the best quality of care is provided. Communication is one of the key components of bedside nursing practice. Communication ensures that medical errors are avoided, while patient safety and the quality of care are not affected during a patient's stay.

Purpose: The purpose of this study was to compare the risks and benefits of bedside shift report (BSR) versus traditional shift report (TSR).

Method: For a proper evidence-based review, the studies were precisely analyzed, and systematically pieced using the top four tiers of evidence hierarchy.

Findings: While bedside shift report has been implemented within inpatient settings, it is not always being utilized properly. Upon conclusion of the literature review, evidence supports using bedside shift report to reduce medical errors, safety risks, and improve the quality of care.
\end{abstract}

Keywords: bedside shift report, traditional shift report, risks of shift report, communication

\section{Introduction}

Nursing shift starts and ends with an exchange of patient information known as shift report or handoff. This process, if imprecise, can be risky, influencing the safety of the patient, and the continuity of care (Tobiano, Whitty, Bucknall, \& Chaboyer, 2017). Bedside shift report (BSR) has been implemented for nurse-to-nurse handoff of patient information. This practice was implemented to reduce the risk of patient complications during nurse-to-nurse report and to allow the patient to play an active role in their care. The Situation, Background, Assessment, Recommendation (SBAR) is a tool used in this process to aid in the proper handoff of patient information. While traditional shift report (TSR) can use the same tool, this is a time in which adverse patient complications can occur. TSR is often given within the area of a nursing station, thus allowing the patient to spend time alone. The time the patient spends alone during TSR provides the opportunity for complications and adverse outcomes. Given this potential for complications and adverse outcomes, the research demonstrates the need to utilize BSR over the traditional method of shift handoff. Ensuring proper communication is an essential component of the practice of nursing.

\section{Problem}

Medical errors, safety risks, and quality of care are all problems that have been imposed by lack of communication between nurses. Nursing shift-to-shift reports have historically happened at nursing stations and not at the bedside; report at nursing stations can be interrupted, drawn-out, and inaccurate (Reinbeck \& Fitzsimons, 2013). Although bedside shift report has been implemented within nursing practice, barriers still exist that pose risks to patients. Unfortunately, nurses remain largely unaware of the risks and benefits of bedside report versus traditional report. 


\section{Purpose}

The purpose of this literature review was to compare the potential risks and benefits to the patients when nursing staff implements and uses bedside shift report versus traditional shift report using the problem, intervention, comparison, and outcome (PICO) model of evidence-based practice (EBP).

\section{PICO Question}

Does the implementation and use of bedside shift report by nursing staff reduce the potential risks of adverse outcomes, medication errors, or inaccurate or missing information, while providing benefits within the acute-care setting?

\section{Literature Review}

The literature review was performed through investigation and exploration using Google Scholar, Cumulative Index of Nursing and Allied Health Literature (CINAHL), and Ovid databases. Utilizing the search terms "bedside shift report," "traditional shift report," "risks of shift report," and "communication," a wealth of scholarly and peer-reviewed journal articles were available. The literature selected for review was published from 2013 to 2018 . For a proper evidence-based review, the studies were precisely analyzed, and systematically pieced using the top four tiers of evidence hierarchy.

\subsection{Bedside Shift Report}

Shift report is a communication process that takes place twice within a working day. The process of BSR is a strategy implemented to be more patient-centered during the report process and care. Proper handoffs may be reliant on the communication skill-level of the nurses providing the information. Cairns, Hoffmann, Dudjak, and Lorenz (2013) suggest "an experienced nurse may provide more in-depth information or may conversely assume a baseline of knowledge among peers that may not be present" (p. 160). Shift report that occurs away from the bedside can lack structure and become lengthy, BSR allows for the patient to add insight and ask questions. Cairns et al. (2013) emphasize that "the complexity of today's healthcare environment challenges nurses to communicate in ways that consistently achieve positive outcomes related to quality and safety" (p. 160). BSR was designed to improve communication between nurses; however, there are barriers that persist within the bedside field that allow nurses to still utilize TSR.

\subsection{Traditional Shift Report}

TSR remains in use within the nursing field. The application of TSR potentiates a risk for positive outcomes about patient safety and the quality of care. TSR takes place at a centralized nursing station; with the utilization of TSR a nurse is less likely to see their patients within the first hour of their shift. Ofori-Atta, Binienda, and Chalupke (2015) claim "patients are aware of the change-of-shift time; they know their nurses are at the nurse's station, and for an hour or more they are basically 'alone'" (p. 1). The time the patient spends 'alone,' the more likely a 'sentinel event' could occur (Ofori-Atta et al., 2015). BSR unlike TSR can help eliminate the amount of time a patient is left alone, thus, allowing nurses to lay eyes on the patients within the first 30 minutes of their shift. Radtke (2013) purposes, "this opens the door for misinformation and does not give the patient or their family a venue to exchange information that may be important to the oncoming shift."

\subsection{Patient Safety and Quality of Care}

Falls and medication errors are preventable errors related to patient safety. Ofori-Atta et al. (2015) stated that preventable errors do not "necessarily lead to death, but one that causes injury or disability is devastating to the patient and costly to the institution" (p. 2). Defects in organizational systems and the human component create an opportunity for potential errors, which result in the patient having concerns about their safety during a hospitalization (Ofori-Atta et al., 2015). Patient safety has been the primary reason that BSR has taken precedence over TSR. Transitions within nursing during patient care can create potential risks. BSR provides accountability between the on-coming and off-going nurses to validate care relating to medication changes, IV pump settings, skin issues, and the overall appearance of the patient's condition (Ofori-Atta et al., 2015). Ultimately, BSR ensures that the off-going nurse's tasks have been completed by both nurses, providing continuity in the plan of care and best-practice communication between nursing staff.

\subsection{Nurse Barriers to Bedside Shift Report}

Nurses are concerned that the implementation of BSR increases the length of time it will take to handoff pertinent patient information (Reinbeck \& Fitzsimons, 2013). BSR can be a difficult and stressful process for nurses and is inconsistently applied. In a recent study, a survey was conducted in a 504-bed academic community hospital, with 84 Registered Nurses (RNs), with different degrees and years of experience, about the 
potential barriers and implementation of BSR (Small \& Fitzpatrick, 2017). The authors found "nurses perceive BSR to increase accountability, patient safety, and patient involvement after implementation on either a structured or unstructured basis" (Small \& Fitzpatrick, 2017, p. 48). Barriers and concerns to BSR by nurses are laid out within the research conducted by Ofori-Atta et al. (2015). Concerns raised by nurses were identified within the research conducted to include unknown visitors or family members that may be present, a diagnosis or lab values that the provider has yet to share with the patient, waking up the patient, increased time for report related to questions arising from the patient or family, and Health Insurance Portability and Accountability Act ([HIPAA] Ofori-Atta et al., 2015).

Nurses tend to stray away from BSR for many reasons. Scheidenhelm and Reitz (2017) suggest "addressing staff perceived barriers such as receiving report from too many nurses, interruptions to meet patient needs, confidentiality, and waking patients are issues to address before the implementation of bedside report" (p. 147-148).

\subsection{Implementation of Bedside Shift Report}

While shift hand-offs happen twice a day, the chances of receiving misleading or incomplete information intensify each time information is exchanged (Cairns et al., 2013). Even though BSR has been around for many years, Cairns et al. (2013) find that "despite the demonstrated relationship between communication and patient safety, research suggests that communication hand-offs among nurses are still a challenge today" (p. 161). A project was conducted in a large tertiary academic hospital in Pennsylvania on a 23-bed unit to measure the effects of restructuring report. This project was "measured by the amount of end-of-shift overtime, frequency of call light usage during change-of-shift times, patient's perceptions of being involved in care, and staff's perceptions of its effects of limitations identified in the existing method of automated shift report" (Cairns et al., 2013, p. 161). However, organizational leaders will need to continue to implement EBP in the quickly shifting healthcare field, providing education, resources, and support to succeed with the modifications (Scheidenhelm \& Reitz, 2017).

\section{Summary of Research Evidence}

To decrease potential risks to patients, increase the quality of care and patient satisfaction scores, organizational leaders have implemented BSR. The intention of this systematic review was to compare the use of BSR versus TSR. Although there is more research on the implementation of BSR than TSR, it shows that BSR allows for nurses to see their patients within the first hour of the shift. Decreasing the time, the patient is 'alone' during report and ultimately decreases the potential risks that could happen during the change-of-shift.

Reinbeck and Fitzsimons (2013) noted bedside report encourages an environment for "mentoring relationships" and creates mutual respect among staff, and "nurses are able to visualize patients and implement safety checks at the start of the shift, reducing the length of time they spend at the nurses' station and away from the bedside" (p. 17). Through the research conducted by Ghosh, Curl, Goodwin, Morrell, and Guidroz, (2018) related to standardized pre-printed report concludes, "the findings are a call-to-action to focus attention on designing handoff forms/pre-printed reports that reduce nurses' cognitive 'burden; in particular, research should focus on data and information 'elements' to be included in the pre-printed report that suit the specific needs of nurses based on the unit they are assigned and the individual needs of their patients" (p. 3186). After analyzing the literature, it is important to point out that the implementation of BSR can be challenging for nurses but can significantly reduce potential risks, such as falls and adverse effects of patient care.

\section{Recommendations for Practice}

While BSR within organizations is still inconsistent with the nursing practice, changes must be implicated to meet healthcare standards. Bedside report allows the nurse to visually meet and see their patient within the first 30 minutes of their shift. Allowing the nurse to evaluate potential risks to the patient, ensuring the patient will know who is taking care of them, thus ensuring the bed alarm is on preventing falls and future harm to the patient.

BSR could be challenging to uphold within the acute-care setting. For BSR to be sustained within nursing practice, it will need to involve leadership from management and senior nurses. Implementation of BSR is shown to be the standard of care that provides the highest level of patient safety and patient-centered care.

\section{Conclusion}

BSR has become the most highly recommended way in which nurse's transition patient care from one shift to the next. Whether BSR is standardized or unstandardized, nurses have perceived barriers to providing bedside report. Overcoming these barriers and utilizing BSR instead of TSR can decrease the potential risks to patients during 
the 'alone' period. Nursing staff need to recognize, while barriers will persist, BSR is standard to patient hand-off. Research has shown significant evidence to support the use of BSR to improve patient safety, as well as increased patient and staff satisfaction rates. However, further studies need to be more specific in analyzing the cause for possible sentinel events during shift change.

\section{References}

Cairns, L.L., Hoffmann, R.L., Dudjak, L.A., \& Lorenz, H.L. (2013). Utilizing bedside shift report to improve the effectiveness of shift handoff. The Journal of Nursing Administration, 43(3), 160-165. https://doi.org/10.1097/NNA.0b013e318283dc02

Ghosh, K., Curl, K., Goodwin, M., Morrell, P., \& Guidroz, P. (2018). An exploratory study on how to improve bedside change-of-shift process: Evidence from one hospital using technology to support verbal reporting. Hawaii International Conference on System Sciences, 3180-3187. https://doi.org/10.24251/HICSS.2018.401

Ofori-Atta, J., Binienda, M., \& Chalupke, S. (2015). Bedside shift report: Implications for patient safety and quality of care. Nursing, 45(8), 1-4. https://doi.org/10.1097/01.NURSE.0000469252.96846.1a

Radtke, K. (2013). Improving patient satisfaction with nursing communication using bedside shift report. Clinical Nurse Specialist, 27(1), 19-25. https://doi.org/10.1097/NUR.0b013e3182777011

Reinbeck, D.M., \& Fitzsimons, V. (2013). Improving the patient experience through bedside shift report. Nursing Management, 44(2), 16-17. https://doi.org/10.1097/01.NUMA.0000426141.68409.00

Scheidenhelm, S., \& Reitz, O.E. (2017). Hardwiring bedside shift report. The Journal of Nursing Administration, 47(3), 147-153. https://doi.org/10.1097/NNA.0000000000000457

Small, D.C., \& Fitzpatrick, J.J. (2017). Nurse perceptions of traditional and bedside shift report. Nursing Management, 48(2), 44-49. https://doi.org/10.1097/01.NUMA.0000511921.67645.47

Tobiano, G., Whitty, J.A., Bucknall, T., \& Chaboyer, W. (2017). Nurses' perceived barriers to bedside handover and their implication for clinical practice. Worldviews on Evidence-Based Nursing, 14(5). https://doi.org/10.1111/wvn.12241

\section{Copyrights}

Copyright for this article is retained by the author(s), with first publication rights granted to the journal.

This is an open-access article distributed under the terms and conditions of the Creative Commons Attribution license (http://creativecommons.org/licenses/by/4.0/). 